\title{
A study on nutritional status of elderly and its correlates from urban field practice areas of SGRRIM\&HS, Dehradun
}

\author{
Megha Luthra ${ }^{1}$, K.S. Negi ${ }^{2}$, Puneet Ohri ${ }^{3}$,* \\ ${ }^{1}$ Professor, ${ }^{2}$ Professor Biostatistics, ${ }^{3}$ Professor and Head, Dept. of Community Medicine, Shri Guru Ram Rai Institute of Medical \\ and Health Sciences, Dehradun, Uttarakhand, India \\ *Corresponding Author \\ Email: ohri7puneet@ rediffmail.com
}

\begin{abstract}
Introduction: Number of elderly persons is rapidly increasing worldwide, mostly in developing countries. The elderly are at increased risk of nutritional inadequacy which, if detected in time, can be reversed. A comprehensive nutritional assessment tool called Mini Nutritional Assessment (MNA) has been confirmed to detect malnutrition in the elderly with reasonable accuracy.

Aims and Objectives: To detect the prevalence and correlates of malnutrition in the elderly.

Materials and Methods: A cross-sectional study was carried out in urban field practice area of Department of Community Medicine, SGRRIM\&HS, Dehradun using a pre designed, pre tested questionnaire filled by trained health teams. Data was analyzed with SPSS version 23.

Result: Prevalence of malnutrition in elderly was found to be $32.2 \%$ which is significantly associated with changes in food intake and weight over past three months, mobility, neuropsychological problems, acute disease/psychological stress and BMI.

Conclusion: Malnutrition in the elderly can be managed with a multi-disciplinary approach that treats the pathology as well as uses social and dietary interventions.
\end{abstract}

Keywords: Nutritional status, Elderly, Mini nutritional assessment.

\section{Introduction}

United Nations has defined elderly as people aged 60 years and above. Percentage of the elderly is rapidly increasing worldwide; their global number is projected to rise from an estimated 524 million in 2010 to nearly 1500 million in 2050. Most of this increase is expected to be in developing countries. ${ }^{1}$ In India, percentage of elderly has increased to $8.6 \%$ of total population ${ }^{2}$ from $7.5 \%$ as shown by Census 2001. There is a rising old age dependency ratio i.e. old as a percent of working age population from 5\% in 1960 to $9 \%$ in $2016 .{ }^{3}$ The elderly are at risk of nutritional inadequacy due to physiologic, pathologic, sociologic and psychologic factors. If addressed early, this malnutrition can be reversed. Its management requires a multi-disciplinary approach that offers therapy for pathology as well as uses social and dietary interventions. Unintentional weight loss and malnutrition not responding to interventions are important clinical indicators of worsening health status. ${ }^{4}$ A distinct state called failure to thrive has been described in the elderly. ${ }^{5}$ It is a state of decline with multi-factorial aetiology and may be caused by chronic concurrent diseases and functional impairments. Four syndromes are prevalent and predictive of adverse outcomes in patients with failure to thrive are: Impaired physical function, Malnutrition, Depression and Cognitive impairment. These syndromes have been considered in a comprehensive nutritional assessment tool called Mini Nutritional Assessment (MNA). This tool was introduced and validated for clinical use a little less than 20 years ago. ${ }^{6}$ Since then there has been diffusion among health care professionals and a large body of data has been collected supporting its use in various settings. It has been confirmed that in older populations prevalence of malnutrition by this tool is associated with level of dependence. On the other hand there is risk of overdiagnosis by using this tool. ${ }^{7}$ It has been shown to have 92\% accuracy when compared with a clinical evaluation by two physician specialists in nutrition. On the other hand, when compared with a comprehensive nutritional assessment including biochemical analysis, anthropometric measurements and dietary assessment, it was found to have $98 \%$ accuracy. ${ }^{8}$

\section{Materials and Methods}

A cross-sectional study was carried out in urban field practice area of Department of Community Medicine, SGRRIM\&HS, Dehradun. This area with 14 localities, covering a population of 15,190 . The estimated elderly population is 1246. Probability proportional to size method with sampling interval calculation and random selection of first house was applied to select elderly subjects from each locality. Total sample size was kept to be more than $10 \%$ of the sampling frame of 1246 elderly (Purposive sampling). A pre designed, pre tested questionnaire was the main tool of investigation which further consisted of MNA for nutritional status, Geriatric Depression Scale (GDS) for findings suggestive of depression and Mini Cog Assessment (MCA) for findings suggestive of cognitive impairment in dementia. Screening score for MNA was a maximum of 14 points. A subject scoring 12-14 points was considered as normal nutritional status, 8-11 points as at risk of malnutrition and $0-7$ points as 
malnourished. For GDS a score of 0-5 is normal and a score above 5 suggests depression. In MCA a score of 1 or 2 is suggestive of mild cognitive impairment where as scores of 3,4 and 5 are considered to suggest normal cognitive status. The study was carried out by health teams trained to fill the questionnaires, which in turn were reviewed on a daily basis. Study period was $1^{\text {st }}$ Nov 2017 to $28^{\text {th }}$ Feb 2018. Data entry was done in Microsoft excel and statistical analysis was carried out with help of SPSS version 23.

\section{Results}

152 subjects were taken up for the purpose of this study. $109(71.7 \%)$ subjects were in age group of 60-74 years, $37(24.3 \%)$ subjects were in age group of $75-84$ years and $6(3.9 \%)$ subjects were aged 85 years and above (Table 1). $88(58 \%)$ subjects were males and $64(42 \%)$ subjects were female (Table 2). Frequency analysis of MNA score showed that $100(65.8 \%)$ subjects were normal, 49(32.2\%) subjects were at risk of malnutrition and $3(1.9 \%)$ subjects were malnourished. Majority, 133(87.5\%) subjects did not complain of any decrease in food intake over the last three months. Hence majority, 120 (79\%) subjects had no weight loss over the last three months. When the physical function was assessed in terms of mobility, only $1(0.7 \%)$ subject was bed bound, $12(7.9 \%)$ subjects were confined to their homes and $139(91.4 \%)$ subjects were fully mobile that is doing indoor as well as outdoor chores. With respect to acute disease or acute psychological stress, only $16(10.5 \%)$ subjects had experienced either of the above in last three months.

When neuropsychological problems were assessed with help of previous history, GDS and MCA scores, it was found that majority, i.e. 82(53.9\%) subjects had findings suggestive of depression or dementia and $7(4.6 \%)$ subjects were known cases of severe dementia or depression who could not be left unsupervised by their family members. Rest of 63(41.5\%) subjects had no psychological problems.

In terms of Body Mass Index (BMI), nearly a third of the subjects that is $48(31.6 \%)$ subjects had BMI within the range considered normal for the purpose of this study (19 to less than 23) from the MNA schedule (Table 3).

Further analysis of the MNA scores showed that nutritional status of the elderly is significantly associated with age, changes in food intake and weight over past three months, mobility, neuropsychological problems, acute disease/psychological stress and BMI (Tables 1, $2 \& 3$ ).

In addition to all these parameters of MNA, nutritional status of the elderly was also significantly associated with Geriatric Depression Scale score (possibility of depression) and Mini-Cog Assessment score (possibility of cognitive impairment) (Tables 4 and 5).

Table 1: Distribution of Age and MNA score

\begin{tabular}{|l|c|c|c|c|}
\hline \multicolumn{1}{|c|}{ Age } & \multicolumn{3}{c|}{ MNA Score } & \multirow{2}{*}{ Total } \\
\cline { 2 - 4 } & Normal & At Risk of Malnutrition & Malnourished & \\
\hline 60-74 years & $80(80 \%)$ & $28(57.1 \%)$ & $1(33.3 \%)$ & $109(71.7 \%)$ \\
\hline 75-84 years & $19(19 \%)$ & $17(34.7 \%)$ & $1(33.3 \%)$ & $37(24.3 \%)$ \\
\hline 85 years and above & $1(1 \%)$ & $4(8.2 \%)$ & $1(33.3 \%)$ & $6(3.9 \%)$ \\
\hline Total & 100 & $49(100.0 \%)$ & $3(100.0 \%)$ & $152(100.0 \%)$ \\
\hline
\end{tabular}

\section{Chi Square value $=22.2 \mathrm{p}<0.01$ Significant}

$109(71.7 \%)$ subjects were in age group of 60-74years, $37(24.3 \%)$ subjects were in age group of $75-84$ years and $6(3.9 \%)$ subjects were aged 85 years and above.
The association between age and nutritional status was found to be statistically significant $(\mathrm{p}<0.01)$

Table 2: Distribution of Sex and MNA Score

\begin{tabular}{|l|c|c|c|c|}
\hline \multirow{2}{*}{ Sex } & \multicolumn{3}{c|}{ MNA Score } & Total \\
\cline { 2 - 5 } & Normal & At Risk of Malnutrition & Malnourished & \\
\hline Female & $36(36 \%)$ & $26(53.1 \%)$ & $1(33.3 \%)$ & $63(41.4 \%)$ \\
\hline Male & $64(64 \%)$ & $23(46.9 \%)$ & $2(66.6 \%)$ & $89(58.5 \%)$ \\
\hline Total & $100(100 \%)$ & $49(100.0 \%)$ & $3(100.0 \%)$ & $152(100.0 \%)$ \\
\hline
\end{tabular}

Chi Square Value=3.99 p >0.05 Not Significant

$89(58.5 \%)$ subjects were males and $63(41.4 \%)$ subjects were female.
The association between sex and nutritional status was not found to be statistically significant $(\mathrm{p}>0.05)$. 
Table 3: Mini Nutritional Assessment

\begin{tabular}{|c|c|c|c|c|c|c|}
\hline & & $\begin{array}{c}\text { Normal } \\
\text { Nutrition }\end{array}$ & $\begin{array}{c}\text { At risk of } \\
\text { malnutrition }\end{array}$ & $\begin{array}{c}\text { Mal- } \\
\text { nourished }\end{array}$ & Total & $\begin{array}{l}\text { Chi Square } \\
\text { and p values }\end{array}$ \\
\hline $\begin{array}{l}\text { Food Intake over last } \\
3 \text { months }\end{array}$ & $\begin{array}{l}\text { Moderate Decrease } \\
\text { No decrease }\end{array}$ & $\begin{array}{c}3(3 \%) \\
97(97 \%)\end{array}$ & $\begin{array}{l}14(28.6 \%) \\
35(71.4 \%)\end{array}$ & $\begin{array}{l}2(66.7 \%) \\
1(33.3 \%)\end{array}$ & $\begin{array}{c}19(12.5 \%) \\
133(87.5 \%)\end{array}$ & $\begin{array}{c}33.6 \\
p<0.01\end{array}$ \\
\hline $\begin{array}{l}\text { Weight loss over last } 3 \\
\text { months }\end{array}$ & $\begin{array}{l}\text { Does not know } \\
1-3 \mathrm{Kgs} \\
\text { No weight loss }\end{array}$ & $\begin{array}{c}0(0 \%) \\
9(9 \%) \\
91(91 \%)\end{array}$ & $\begin{array}{c}1(2 \%) \\
20(40.8 \%) \\
28(57.2 \%)\end{array}$ & $\begin{array}{l}1(33.3 \%) \\
1(33.3 \%) \\
1(33.3 \%)\end{array}$ & $\begin{array}{c}2(1.3 \%) \\
30(19.7 \%) \\
120(78.9 \%)\end{array}$ & $\begin{array}{c}61.3 \\
p<0.01\end{array}$ \\
\hline Mobility & $\begin{array}{c}\text { Bed or chair bound } \\
\text { Does not go out } \\
\text { Goes out }\end{array}$ & $\begin{array}{c}0(0 \%) \\
4(4 \%) \\
96(96 \%)\end{array}$ & $\begin{array}{c}1(2 \%) \\
6(12.2 \%) \\
42(85.7 \%)\end{array}$ & $\begin{array}{c}0(0 \%) \\
2(66.7 \%) \\
1(33.3 \%)\end{array}$ & $\begin{array}{c}1(0.7 \%) \\
12(7.9 \%) \\
139(91.4 \%)\end{array}$ & $\begin{array}{c}29.2 \\
p<0.01\end{array}$ \\
\hline Acute Disease & $\begin{array}{l}\text { Yes } \\
\text { No }\end{array}$ & $\begin{array}{c}2(2 \%) \\
98(98 \%)\end{array}$ & $\begin{array}{l}12(24.5 \%) \\
37(75.5 \%)\end{array}$ & $\begin{array}{l}2(66.7 \%) \\
1(33.3 \%)\end{array}$ & $\begin{array}{c}16(10.5 \%) \\
136(89.5 \%)\end{array}$ & $\begin{array}{c}34.7 \\
p<0.01\end{array}$ \\
\hline \begin{tabular}{|l} 
Neuro \\
psychological \\
Problems
\end{tabular} & $\begin{array}{c}\text { Severe dementia or } \\
\text { depression } \\
\text { Mild dementia } \\
\text { No psychological } \\
\text { problems }\end{array}$ & $\begin{array}{c}0(0 \%) \\
50(50.0 \%) \\
50(50.0 \%)\end{array}$ & $\begin{array}{l}5(10.2 \%) \\
31(63.2 \%) \\
13(26.5 \%)\end{array}$ & $\begin{array}{c}2(66.7 \%) \\
1(33.3 \%) \\
0(0 \%)\end{array}$ & $\begin{array}{c}7(4.6 \%) \\
82(53.9 \%) \\
63(41.4 \%)\end{array}$ & $\begin{array}{c}54.5 \\
p<0.01\end{array}$ \\
\hline BMI & $\begin{array}{c}<19 \\
19<21 \\
21<23 \\
23 \text { or greater } \\
\end{array}$ & $\begin{array}{c}1(1 \%) \\
8(8 \%) \\
14(14 \%) \\
77(77 \%) \\
\end{array}$ & $\begin{array}{l}13(26.5 \%) \\
16(32.6 \%) \\
10(20.4 \%) \\
10(20.4 \%) \\
\end{array}$ & $\begin{array}{c}1(33.3 \%) \\
1(33.3 \%) \\
0(0 \%) \\
1(33.3 \%) \\
\end{array}$ & $\begin{array}{c}14(9.2 \%) \\
24(15.8 \%) \\
25(16.7 \%) \\
89(58.5 \%) \\
\end{array}$ & $\begin{array}{c}61.2 \\
p<0.01\end{array}$ \\
\hline Total & & $100(65.8 \%)$ & $\begin{array}{c}49 \\
(32.2 \%)\end{array}$ & $\begin{array}{c}03 \\
(1.9 \%)\end{array}$ & $\begin{array}{c}152 \\
(100.0 \%)\end{array}$ & \\
\hline
\end{tabular}

Out of the 152 subjects studied, $100(65.8 \%)$ subjects were normal, $49(32.2 \%)$ subjects were at risk of malnutrition and 3(1.9\%) subjects were malnourished. $133(87.5 \%)$ elderly did not complain of any decrease in food intake over the last three months and $120(78.9 \%)$ subjects had no weight loss over the last three months. Only $1(0.7 \%)$ subject was bed bound, $12(7.9 \%)$ subjects were confined to their homes and $139(91.4 \%)$ subjects were fully mobile that is doing indoor as well as outdoor activities. 16(10.5\%) subjects had experienced either acute disease or acute psychological stress in last three months. Neuropsychological problems were assessed with help of previous history, GDS and MCA scores.
82(53.9\%) subjects had findings suggestive of depression or dementia and 7(4.6\%) subjects were known cases of severe dementia or depression who could not be left unsupervised by their family members. $63(41.5 \%)$ subjects had no psychological problems. 49(32.3\%) subjects had BMI within the range considered normal for the purpose of this study (19 to less than 23) from the MNA schedule.

Also nutritional status of the elderly is significantly associated with changes in food intake and weight over past three months, mobility, neuropsychological problems, acute disease/psychological stress and BMI $(\mathrm{p}<0.01)$

Table 4: Distribution of MNA Score with respect to Geriatric Depression Scale

\begin{tabular}{|l|c|c|c|c|}
\hline \multirow{2}{*}{ GDS Score } & \multicolumn{3}{|c|}{ MNA Score } & \multirow{2}{*}{ Total } \\
\cline { 2 - 5 } & Normal & At Risk of Malnutrition & Malnourished & \\
\hline Normal & $87(87 \%)$ & $35(71.4 \%)$ & $0(0 \%)$ & $122(80.2 \%)$ \\
\hline $\begin{array}{l}\text { Suggestive of } \\
\text { Depression }\end{array}$ & $13(13 \%)$ & $14(28.6 \%)$ & $3(100 \%)$ & $30(19.7 \%)$ \\
\hline Total & $100(100 \%)$ & $49(100 \%)$ & $3(100 \%)$ & $152(100 \%)$ \\
\hline
\end{tabular}

\section{Chi Square Value $=13.7 p<0.01$ Significant}

Of all the elderly studied, 30(19.7\%) had findings suggestive of depression. 13 of them were normally nourished, 14 were at risk of malnutrition and 3 were malnourished. The association between depression and nutritional status was found to be statistically significant $(\mathrm{p}<0.01)$

Table 5: Distribution of MNA Score with respect to Mini Cognitive Assessment

\begin{tabular}{|l|c|c|c|c|}
\hline \multirow{2}{*}{ MNA Score } & \multicolumn{3}{|c|}{ MNA Score } & \multirow{2}{*}{ Total } \\
\cline { 2 - 5 } & Normal & At Risk of Malnutrition & Malnourished & \\
\hline Normal & $60(60 \%)$ & $20(40.8 \%)$ & $1(33.33 \%)$ & $80(52.6 \%)$ \\
\hline $\begin{array}{l}\text { Suggestive of } \\
\begin{array}{l}\text { Cognitive } \\
\text { Impairment }\end{array}\end{array}$ & $40(40 \%)$ & $29(59.2 \%)$ & $2(66.66 \%)$ & $72(47.4 \%)$ \\
\hline Total & $100(100 \%)$ & & & \\
\hline
\end{tabular}

\section{Chi Square value $=7.14 p<0.05$ Significant}


$72(47.4 \%)$ subjects had findings suggestive of cognitive impairment. Out of these 40 were normally nourished, 29 were at risk of malnutrition and 3 were malnourished. The association between nutritional status of elderly and cognitive impairment was found to be statistically significant $(\mathrm{p}<0.05)$

\section{Discussion}

In the present study 152 subjects were included. $109(71.7 \%)$ subjects were aged $60-74$ years, $37(24.3 \%)$ subjects were aged $75-84$ years and 6(3.9\%) subjects were aged 85 years and above. $89(58.5 \%)$ subjects were males and $63(41.4 \%)$ subjects were females. In $133(87.5 \%)$ subjects there was no decrease in food intake over the last three months. Also 120 (78.9\%) subjects had experienced no weight loss over the last three months. However, of the remainder of subjects $19(12.5 \%)$ complained of moderate decrease in food intake over the last three months, 30(19.7\%) subjects had $1-3 \mathrm{~kg}$ weight loss.

When mobility was taken to represent physical function, there was $1(0.7 \%)$ subject who was bed bound, $12(7.9 \%)$ subjects were confined to their homes and $139(91.4 \%)$ subjects were doing indoor as well as outdoor work that is were fully mobile. When acute disease or acute psychological stress was considered, only $16(10.5 \%)$ subjects had experienced acute disease or psychological stress in last three months.

In terms of neuropsychological problems assessed with help of previous history, GDS and MCA scores, it became evident that most, i.e. $82(53.9 \%)$ subjects had findings suggestive of depression or dementia and $7(4.6 \%)$ subjects could not be left unsupervised by their family members and were known cases of severe dementia or depression. Remaining 63(41.5\%) subjects had no psychological problems.

Upon examining nutritional status of subjects with help of Body Mass Index (BMI), it was observed that nearly a third of the subjects that is $49(32.3 \%)$ had BMI within the range considered normal for the purpose of this study (19 to < less than 23) as taken up from MNA form. Frequency analysis of MNA score showed that $100(65.8 \%)$ subjects were normal, $49(32.2 \%)$ subjects were at risk of malnutrition and $3(1.9 \%)$ subjects were malnourished. Analysis of the MNA scores for strength of association showed that nutritional status of the elderly is significantly associated with age, changes in food intake and weight over past three months, mobility, neuropsychological problems, acute disease/ psychological stress and BMI. In addition to all these parameters of MNA, nutritional status of the elderly was also significantly associated with GDS score (possibility of depression) and MCA score (possibility of cognitive impairment).

In a cross sectional study performed in Nursing Homes in urban area of city of Salvador, Bahia, Brazil using MNA by Amorium SPML et al, it was found that higher percentage than present study i.e.66.3\% of subjects were malnourished or risk of malnutrition. This could be due to two reasons: lower age limit of subjects 60 years and inclusion of institutionalized subjects. Although prevalence of these conditions was higher in men $(76.6 \%)$ than in women $(62.4 \%)$, multivariate analysis revealed only a weak negative correlation between MNA total score and age with $\mathrm{r}=0.159$ and $\mathrm{p}=0.002$ (9). In another cross sectional study by Hallaj FA, a total of 103 elderly people in 3 residential homes were interviewed individually using MNA scale and anthropometric measurements were also carried out. No association of MNA score and sex of subjects was found as in present study. ${ }^{10}$ The fact that nutritional status varies according to mobility in acute geriatric patients using MNA as well as other parameters has been demonstrated in other studies as well. ${ }^{11,12}$ This association remained after adjusting for health status. Schrader et al in a cross sectional study found that taking Activities of Daily Living (ADL) as indicator of mobility, lower MNA score was significantly associated with risk of being dependent (OR 0.85, 95CI, 0.77 to 0.94$)$. Klesswetter E. in their study used MNA and functional status of Geriatrics by instrumental \& basic activities of daily living (IADL, ADL). It was observed functional status deteriorated significantly from the well nourished the malnourished group in all functional measures including IADL, ADL, Timed up \& go test. ${ }^{13}$ Guigoz. Y et al found $1 \%$ prevalence of malnutrition in community dwelling elderly persons, and the prevalence was found to increase upto $30 \%$ in institutionalized elderly persons. They found MNA in home care patient is related to living condition meal patterns and chronic medical condition and also functional status is related to malnutrition. ${ }^{14}$ In a study done by Ramlall $\mathrm{S}$ et al in Africa in a group of residential homes in the elderly and assessed by psychiatrists, contrary to the findings of the current study it was found that although mild cognitive impairment was significantly associated with lower educational level there was no association between depression and dementia or MCI. ${ }^{15}$ Mantzorou et al found a high prevalence of malnutrition in an elderly population sample which was directly associated with cognitive impairment and depression. Diagnostic tools such as MNA, MMSE and GDS were strongly recommended to be applied as a routine clinical practice in the elderly to timely and effectively address these health problems. ${ }^{16}$ In a population based study in Poland it was found that poor nutritional status in the elderly is strongly related to the occurrence of symptoms of depression. People in advanced age with symptoms of depression, cognitive impairment, multimorbidity, anemia and total edentulism should be screened and monitored for early symptoms of malnutrition. ${ }^{17}$ In a review article by Daradkeh $G$ et al it was seen that frailty, chronic conditions and declining cognitive functioning adversely affects nutritional status of senior citizens. Poor nutritional status also has 
adverse effect on the above said conditions. ${ }^{18}$ In a clinical study by Guligowska et al it was reported that inappropriate nutrients intake is associated with lower function status and inferior quality of life in older adults. Incidence of falls and poor quality of life may also be partially associated with presence of depression. Inappropriate intake of selected nutrients may impair the functioning and quality of life of older adults with depression. ${ }^{19}$

Meeting the diet and nutrition needs of older people is crucial for maintenance of health, functional independence and quality of life. Functional status of the elderly determines their ability to perform basic self care tasks and live independently, which also includes food intake. The association between functional and nutritional status was found to be significant and the finding corroborated with other studies. ${ }^{20-22}$ Worldwide, osteoarthritis is the most common articular disease of people 65 years and older- its prevalence in certain elderly group is as high as $85 \%$ and this is a major limiting factor for mobility. That osteo-arthritis significantly increases with increasing BMI, has been shown from a north Indian city also. ${ }^{22}$ A correlation between under-nutrition and poor cognition was shown in an Indian study ${ }^{23}$ and a study from Sri Lanka as well. ${ }^{24}$ As far as mental condition of the elderly is concerned, it has been concluded from different studies that the strongest risk factors for malnutrition in the elderly are unintended weight loss, depression and lowered food intake. Malnutrition and depression are highly prevalent in the elderly and can lead to unfavorable outcomes. Depression has also been associated with worsening nutritional status. ${ }^{25-26}$

\section{Conclusion}

Nutritional status of the elderly is significantly associated with age, changes in food intake and weight over past three months, mobility, neuropsychological problems, acute disease/psychological stress and BMI. In addition to all these parameters of MNA, nutritional status of the elderly was also significantly associated with possibility of depression and possibility of cognitive impairment.

\section{Recommendations}

The elderly are at risk of nutritional inadequacy due to physiologic, pathologic, sociologic and psychological factors. If detected and treated early, this malnutrition is reversible. It can be managed with a multi-disciplinary approach that treats the pathology as well as uses social and dietary interventions.

\section{Limitation of Study}

A further detailed analysis and confirmation of correlates of malnutrition thus observed would have bzen possible as part of a larger project only.

\section{Relevance of study}

The relevance of this study lies in what we can do in the area of study which was newly adopted and requires baseline information for further planning of action.

\section{Acknowledgements}

We extend our sincere thanks to all members of Department of Community Medicine for their team work and support

\section{References}

1. Global Health and Ageing. National Institute on Aging, National Institutes of Health, United States: NIH Publication 2011.

2. Census of India. Registrar General of India office, Government of India; 2011.

3. Data.worldbank.org/indicator/SP.POP.DPND.OL

4. Evans C. Malnutrition in the Elderly: A Multifactorial Failure to Thrive. Perm J. 2005;9(3):38-41.

5. Robertson RG, Montagini M. Geriatric Failure to Thrive. Am Fam physician 2004;70(2):343-50.

6. Vellas B, Guigoz Y, Garry PJ, Nourhashemi F, Bennahum D, Lauque S, Albarede JL. The Mini Nutritional Assessment (MNA) and its use in grading the nutritional state of elderly patients. Nutrition 1999;15(2):116-22.

7. Cereda Emanuele. Mini Nutritional Assessment. Current Opinion in Clinical Nutrition and metabolic care 2012;15(1):29-41.

8. Agarwalla R, Saikia AM, Baruah R. Assessment of Nutritional Status of Elderly and its Correlates. Journal of Family and Community Medicine2015;22(1):39-43.

9. Amorim SPML, deAlmeida MP, Cunha d Oliviera C, CArneriro RAK, Terseopolis RAM, Lima MA et al. Nutritional status of institutionalized elderly Brazilians: a study with MNA. Nutr Hsp. 2014;31(3):1198-204

10. Hallaj FA. Assessment of Nutritional Status of Residents in homes for the elderly in Lattakia, Syrian Arab Republic. East Mediterr Health J. 2015;21(10):753-61.

11. Schrader E, Baumgartel C, Gueldenzoph H, Stehle P, Uter W, Sieber CC et al. Nutritional status according to mini nutritional assessment is related to functional status in geriatric patients- independent of health status. J Nutr Health Aging. 2014;18(3):257-63.

12. Leslie W, Hankey C. Aging, Nutritional Status and Health. Healthcare. 2015;3(3):648-658.

13. Keisswetter E, Pohlhansen S. Uhlig K, Diekmann R, Lessea $\mathrm{S}$, Hesseker $\mathrm{H}$ et al. Malnutriton is related to functional impairment in older adults receiving home care. J Nutr Health Aging. 2013;17(4):345-50

14. Guigoz Y, Lanque S, Vellas BJ. Identifying the elderly at risk for malnutrition. The mini nutritional assessment. Clin Geriatr Med. 2002;18(4):737-57.

15. Ramlall S, Chipps J, Pillay BJ, Bhiggee AL. Mild cognitive impairment and dementia in a heterogenous elderly ppuilation: prevalence and risk profile. Afr $J$ Psychiatry (Johanessberg). 2013;16(6):462-468.

16. MantzorouM, Vadikolias K, Pavildou E, Serdari A, Vasios G, Tryfonoc C et al. Nutr Neurosci. 2018;:1-9. Doi 10.1018/10284

17. Kryminska-Siemaszko R, Chudek J, Suwalska A, Lewandowicz M, Mossakowska M, Kroll-Balcerzak R. Health Status Correlated of Polish elderly populationResults of the Polsenior study. Eur Rev Med Pharmacol Sci. 2016;20(21):4565-4573. 
18. Daradkeh G, essa MM, Al-Adawi SS, koshy RP, Al-Asmi A, Waly MI. Nutritional Status and Cognitive impairment in elderly. Pak J Biol Sci. 2014;17(10):1098-105.

19. Guligowska A, Piglowska M, Fife E, Kotska J, Soltysik BK, Kroc L, Kotska T. Inappropriate nutrients intake is associated with lower function status and inferior quality of life in older adults with depression. Clin Inter Aging. 2016;21(11):1505-1517.

20. Shahar S, Ibrahim Z, Fatah AR, Rahman SA, Yusoff NA, Arshad F et al. A multi-dimensional assessment of health and nutritional status of rural eldrly in Malaysia. Asia Pac J Clin Nutr. 2007;16:346-53.

21. Oliviera MR, Fogaca KC, Leandro-Merhi VA:

Nutritional Status and functional capacity of hospitalized elderly. Nut J. 2009;17(8):54.

22. Sharma MK, Swami HM, Bhatia V, Verma A, Bhatia S, Kaur G. An epidemiological Study of correlates of osteoarthritis in geriatric population of UT Chandigarh. Indian J Community Med. 2007;32:77-8.

23. Gambhir IS, Khurana V, Kishore D, Sinha AK, Mohapatra SC. Ind J Psychiatry. 2914;56(4):365-370.

24. Rodrigo C, Perera S, Adhikari M, Rajapakese A, Rajapakese S. Cognitive impairment and symptoms of depression among geriatric patients in a tertiary care unit in Sri Lanka. Indian J psychiatry. 2010;52:279-80.

25. Brabcova I, treslova M, Bartlova S, Vackova J, Tothova $\mathrm{V}$, Motlova L.Risk factors for nutrition in seniors aged $75+$ living in home environment in selected regions of Czech Republic. Cent Eur J Public Health. 2016;24(3):206-10.

26. Ahmedi Sm, Mohammed MR, Mostafavi SA, Keshaverzi S, Kooshesh SMA, Joulaei H et al. Dependence of Geriatric Depression on Nutritional status and anthropometric indices in elderly population. Iran J Psychiatry. 2013;8(2):92-96. 